\title{
PEMANFAATAN LIMBAH SEKAM PADI UNTUK PEMBUATAN KOMPOSIT HAMBAT PANAS MENGGUNAKAN MATRIK RESIN
}

\author{
Ngafwan \\ Teknik Mesin Universitas Muhammadiyah Surakarta \\ Jl.A. Yani Tromol Pos 1 Pabelan Kartasura
}

\begin{abstract}
The paddy husk is often used as material for persevering ice block which means it has good thermal resistance property. The thermal resistance of paddy husk can be used as base for composing new composite material having good thermal resistance property. The material is made by using polyester as binder with composition paddy husk and polyester in 20\%, 30\%, 40\%, 50\% and 60\% of husk volume fraction. The types of composite manufactured are honeycomb and nonhoneycomb composites. The only test that has been carried out is thermal conductivity property. The thermal conductivity decreases as material temperature increases. In honeycomb composite the decrease of thermal conductivity occurred greater than that in non-honeycomb composite.
\end{abstract}

Keywords: honeycomb composite, conductivity, bending strength

\section{PENDAHULUAN}

Sekam padi adalah limbah dari penggilingan padi yang jumlahnya sangat banyak dan nilai ekonomisnya sangat murah. Agar bahan limbah sekam padi ini dapat dipakai sebagai matrial teknik maka limbah sekam padi perlu dikembangkan sebagai bahan komposit yang penggunaannya sesuai sifat fisis dan mekanisnya. Sesuai penggunaannya sekam padi sering dipakai bahan pelindung untuk menyimpan Es artinya sekam padi merupakan bahan hambat panas yang baik.

Sifat hambat panas yang dimiliki sekam padi tersebut perlu pemikiran pengembangan untuk menjadi material komposit baru dengan bahan dasar dari limbah sekam padi untuk dijadikan komposit hambat panas.

Sebagai penelitian awal ini dipilih Resin sebagai matrik dan limbah sekam padi sebagi serat pendek yang disusun secara acak sehingga terbentuk material komposit, karena setiap material mempunyai sifat terhadap fisis dan mekanis, maka melakukan penelitian ini dilakukan uji hambat panas, bending dan impak. Untuk memperoleh sebaran data penelitian maka penelitian ini dilakukan dengan langkah membuat variasi fraksi volume serat bervariasi

Sesuai dengan latar belakang masalah, rumusan masalah dan kajian pustaka, maka penelitian ini adalah mengetahui fenomena sifat hambat panas komposit serat sekam padi dengan matrik resin dengan model honeycomb dan komposit biasa

\section{TINJAUAN PUSTAKA}

Kekuatan ikatan antara matrik dan serat akan menimbulkan tegangan dalam serat Tegangan yang tinggi pada ujung serat menimbulkan adanya aliran plastik dalam matrik logam. Untuk dapat memanfaatkan kekuatan serat yang cukup tinggi, perlu dilakukan pencegahan agar zona plastik dari matrik tidak merambat melampaui tegah-tengah serat, sebelum regangan 
dalam serat mencapai regangan putus (Dieter, 1996).

Pengujian kekuatan tarik, bending dan impak terhadap komposit serat gelas 3 layer dalam bentuk chopped strand mat dengan berat jenis $300 \mathrm{gram} / \mathrm{m}^{2}$ yang dilakukan oleh Dany Yanuar dan Diharjo K (2003), dipeoleh kekuatan tarik sebesar 67,118 $\mathrm{MPa}$, kekuatan bending 175,25 MPa dan kekuatan impak 0,045 J/mm².

Sudiyono dan Diharjo K. (2004), pada pengamatan awal penelitian yang sedang berjalan, menunjukkan adanya indikasi awal kelemahan pada komposit sandwich dengan core foam/PU, yaitu mudah lepasnya ikatan komposit dengan core foam. Hal ini disebabkan oleh sifat foam yang mudah mripil. Jenis core ini tidak cocok untuk digunakan sebagai core komposit sandwich yang menerima beban bending, geser, impak, dan tarik. Core ini hanya cocok untuk beban tekan yang ringan.

Ngafwan dan Diharjo K (2004) dari hasil penelitian komposit sanwitch serat gelas dengan core PVC, kekuatan bending dan impak lebih baik yaitu pada H 2000PVC Core dengan H 100 PVC Core.
Gibson (1994), Untuk memperoleh komposit berkekuatan tinggi penempatan serat disesuaikan dengan geometri serat, arah, distribusi dan fraksi volume. Komposit yang susunannya lamina unidirectional, serat kontinyu dengan jarak antar serat sama, dan direkatkan secara baik oleh matrik, fraksi volume dapat dihitung dengan menggunakan persamaan sebagai berikut (Shackelford, 1992):seperti ditunjukkan pada gambar 1 .

dengan catatan :

$\mathrm{V}_{1}, \mathrm{~V}_{2}, \ldots=$ fraksi volume,

$\mathrm{W}_{1}, \mathrm{~W}_{2}, \ldots=$ fraksi berat

$\rho_{1}, \rho_{2}, \ldots \ldots=$ densitas bahan pembentuk

$$
\begin{aligned}
& V_{1}=\frac{W_{1} / \rho_{1}}{W_{1} / \rho_{1}+W_{2} / V_{2} \ldots \ldots .} \\
& W_{1}=\frac{\rho_{1} V_{1}}{\rho_{1} V_{1}+\rho_{2} V_{2}+\ldots \ldots}
\end{aligned}
$$

Kekuatan komposit dapat ditentukan dengan persamaan (Shackelford, 1992) :

$$
\sigma_{\mathrm{C}}=\sigma_{\mathrm{f}} \mathrm{V}_{\mathrm{f}}+\sigma_{\mathrm{m}} \mathrm{V}_{\mathrm{m}}
$$

\section{Aspek Geometri}

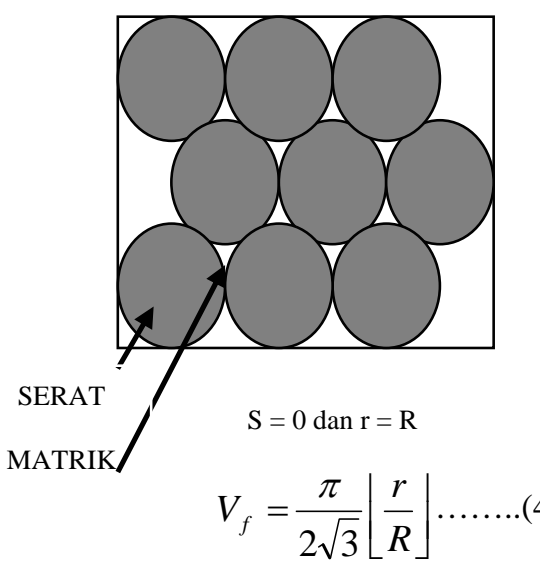

Gambar 1. Komposit dengan serat teratur

$$
\mathbf{S}=\mathbf{0} \text { dan } \mathbf{r}=\mathbf{R}
$$




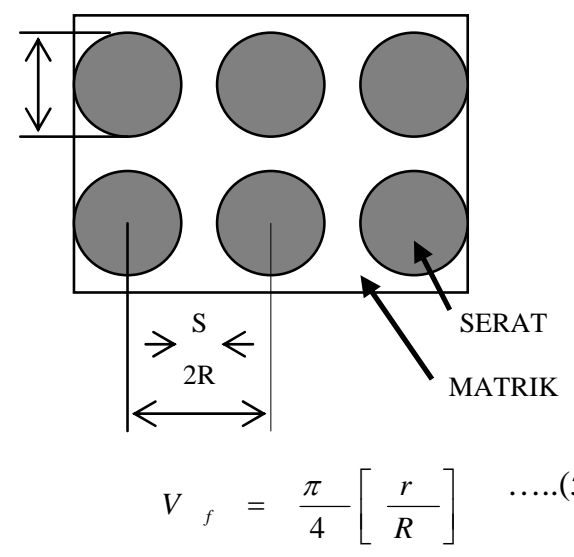

Gambar 2. Komposit dengan serat teratur

$\mathbf{S} \neq \mathbf{0}$

\section{Konduktivitas Panas}

Dalam menghantarkan panas, suatu material pada umumnya mempunyai tiga cara yaitu konduksi, konveksi, dan radiasi. Pada konduksi, panas dialirkan dari satu molekul/atom ke molekul/atom di sampingnya. Arus panas (yaitu panas yang dihantarkan per satuan waktu) sebanding dengan luas penampang yang dilewati panas tersebut. Pengalaman sehari-hari memperlihatkan bahwa panas itu mengalir dari suhu tinggi ke suhu rendah. Sehingga makin besar gradien suatu bahan yang dialiri panas, makin besar arus panas itu.

$$
\begin{aligned}
& q=-k_{a} \cdot A \frac{\Delta T}{\Delta x_{a}}=-k_{b} \cdot \mathrm{A} \frac{\Delta T}{\Delta x_{b}} \\
& q=\frac{T_{0}-T_{3}}{\Delta x_{a} / k_{a} A+\Delta x_{b} / k_{b} A+\Delta x_{c} / k_{c} A}
\end{aligned}
$$

Dimana :

$q$ : Kalor, (Watt).

$K$ :Konduktivitas thermal, $\left(\mathrm{W} / \mathrm{m}^{\circ} \mathrm{C}\right)$.

$A$ : Luas Penampang, $\left(\mathrm{m}^{2}\right)$.

$\Delta x$ : Tebal, (m)

$\Delta T$ : Kalor yang mengalir, (Watt ).

Komposit Sekam Padi

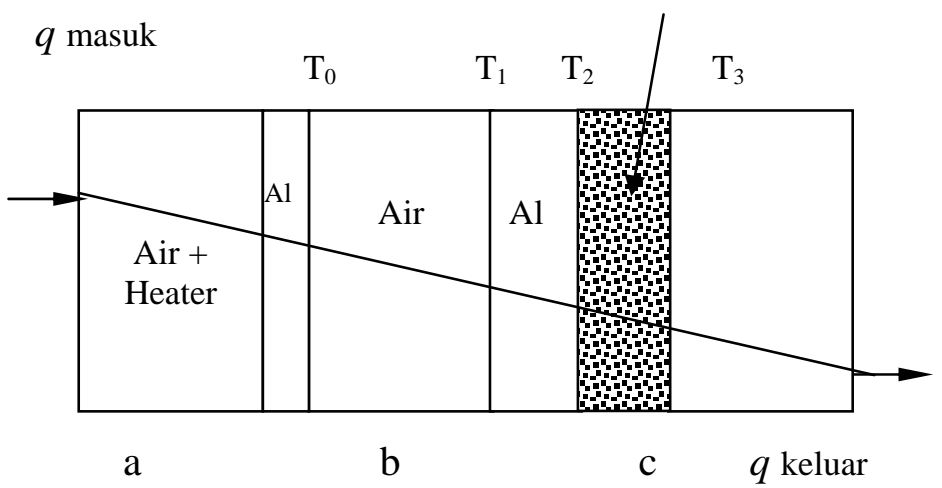

Gambar 3. Cara uji hambat panas 


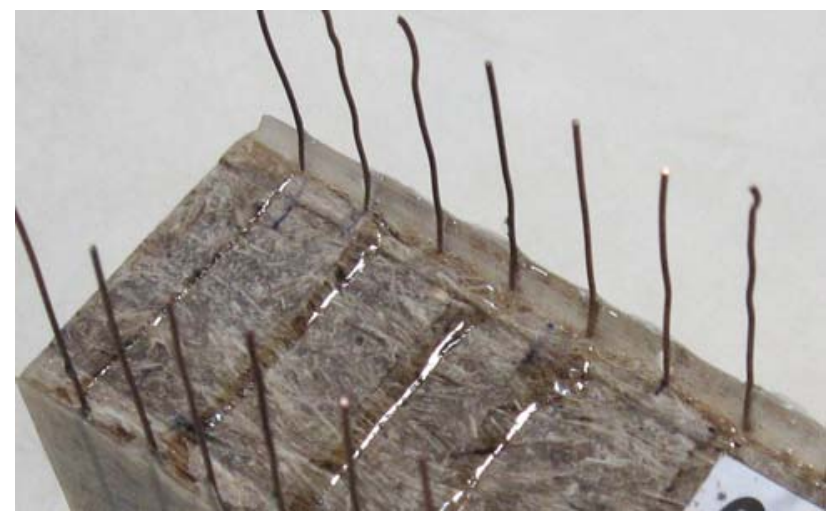

Gambar 4. Spesimen uji panas

\section{METODOLOGI PENELITIAN}

Untuk pengujian hambat panas menggunakan metode seperti gambar 3.20, kotak 1 yang berisi air dipanaskan dengan menggunakan heater sehingga panas akan mengalir dari air dikotak 1 ke alumunium tipis yang berfungsi sebagi kontrol kemudian ke air dikotak 2 lalu ke alumunium tebal dan ke komposit, dari perpindahan kalor tersebut dapat diketahui selisih suhu $(\Delta \mathrm{T})$ sehingga dapat dicari nilai "k" atau konduktivitas komposit.

Pengambilan data pada pengujian dilakukan urutan sebagai berikut:

- $\quad$ Kawat 1-1, 1-2, 1-3, 1-4, 1-5 dan 1-6

- $\quad$ Kawat 2-1, 2-2, 2-3, 2-4, 2-5 dan 2-6

- $\quad$ Kawat 3-1, 3-2, 3-3, 3-4, 3-5 dan 3-6

- $\quad$ Kawat 4-1, 4-2, 4-3, 4-4, 4-5 dan 4-6

- $\quad$ Kawat 5-1, 5-2, 5-3, 5-4, 5-5 dan 5-6

- $\quad$ Kawat 6-1, 6-2, 6-3, 6-4, 6-5 dan 6-6

\section{HASIL DAN PEMBAHASAN}

Hasil uji hambat panas dari berbagai fraksi volume serat yaitu 20\%;40\%;50\% dan 60\% menunjukkan bahwa dengan meningkatnya temperatur spesimen hambat panasnya semakin rendah. Penurunan nilai hambat panas ini dikarenakan dengan meningkatnya temperatur mengakibatkan volume menjadi lebih besar sehingga kepadatan material menjadi berkurang sehingga jarak antar partikel yang berfungsi penghantar panas semakin jauh yang berakibat nilai hantar panas. Dari berbagai komposit dengan fraksi volume serat yang berbeda terlihat bahwa pada komposit fraksi volume serat $50 \%$ terjadi perubahan nilai hambat panas terhadap temperatur yang sangat rendah dan mendekati linier jika dibandingkan dengan fraksi volume yang lain, kejadian ini dikarenakan bahwa pelapisan serat oleh matrik dikatakan simbang di setiap titik sehingga perambatan panas yang terjadi tidak mengalami pembelokan seragam sehingga kesetabilan perambatan panas lebih baik dibandingkan yang lain.

Pada material honeycom menunjukkan bahwa nilai hambat panas pada fraksi volume $50 \%$ sampai $60 \%$ mempunyai nilai yang non linier dibandingkan, namun fenomena ini beda berlawanan dengan material yang tidak honeycomb yaitu grafiknya mengarah pada linier.

Gejala demikian terjadi dua model perpindahan kalor yang pemodelannya 
dapat digambarkan yatu perpindahan kalor konduksi dan gabungan konduksi radiasi pada kondisi beda temperatur relatif kecil dan besar sehingga faktor $\mathrm{T}^{4}$ sangat mempengaruhi harga konduktivitas, seperti pada gambar.

Ditinjau dari perbandingan dua grafik material komposit yang normal dan honeycom seperti pada gambar 5.6 menunjukan bahwa nilai konduktivitas panas pada meterial honeycom lebih linier dan lebih stabil walaupun angka hambat panasnya lebih besar dibandingkan yang material normal.

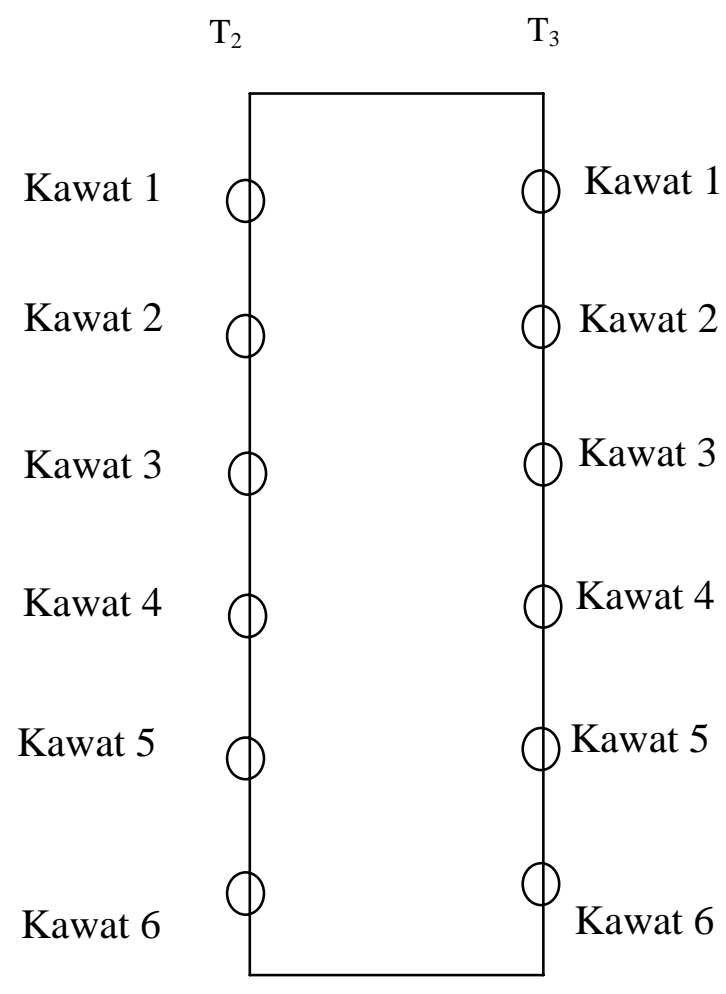

Gambar 5.Skema urutan pencatatan suhu

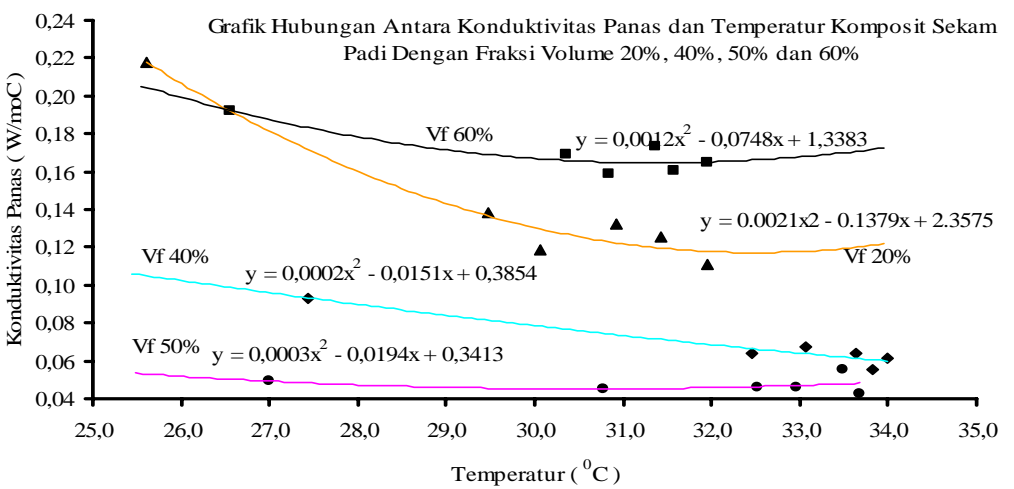

Gambar 6. Hubungan konduktivitas dengan suhu dengan variasi vf 
Grafik Hubungan Antara Konduktivitas Panas dan Temperatur Komposit Sekam

Padi Honeycomb Dengan Fraksi Volume 20\%, 40\%, 50\% dan 60\%

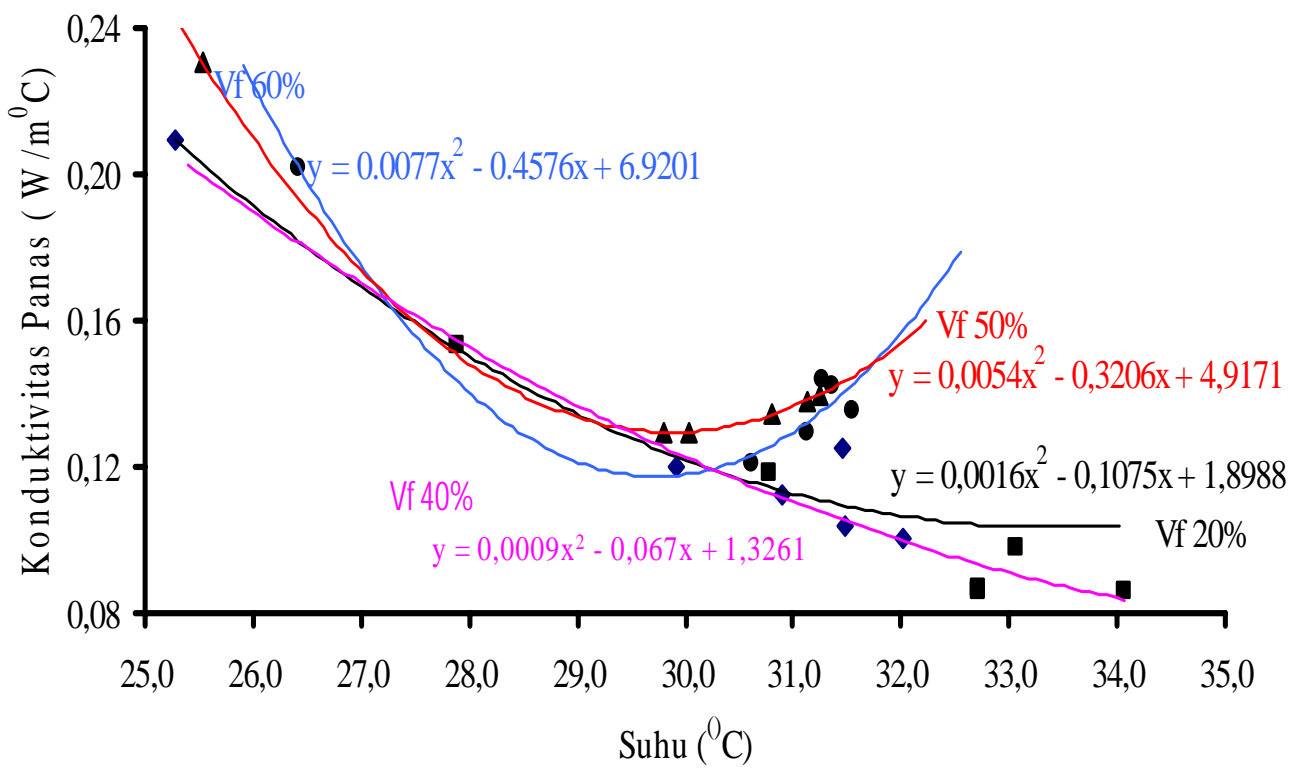

\section{Gambar 7 Hubungan konduktivitas dengan suhu komposit} honeycomb dengan suhu dengan variasi vf

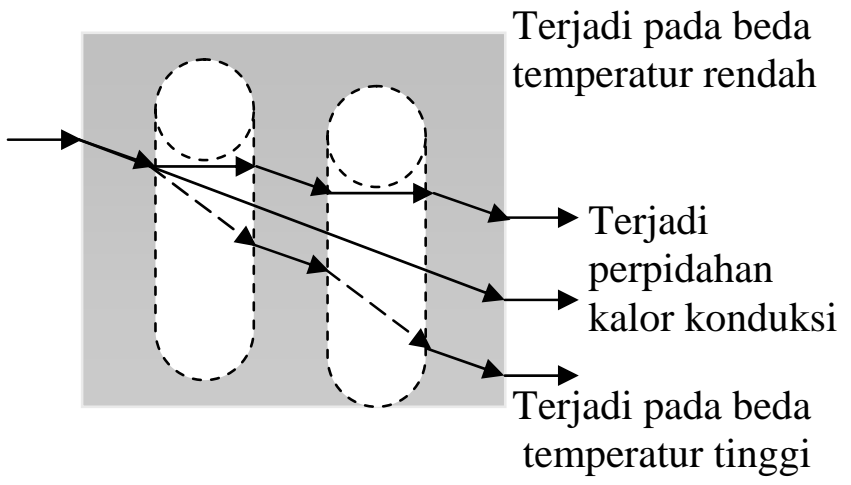

Gambar 8. Fenomena perpindahan kalor pada honeycomb 


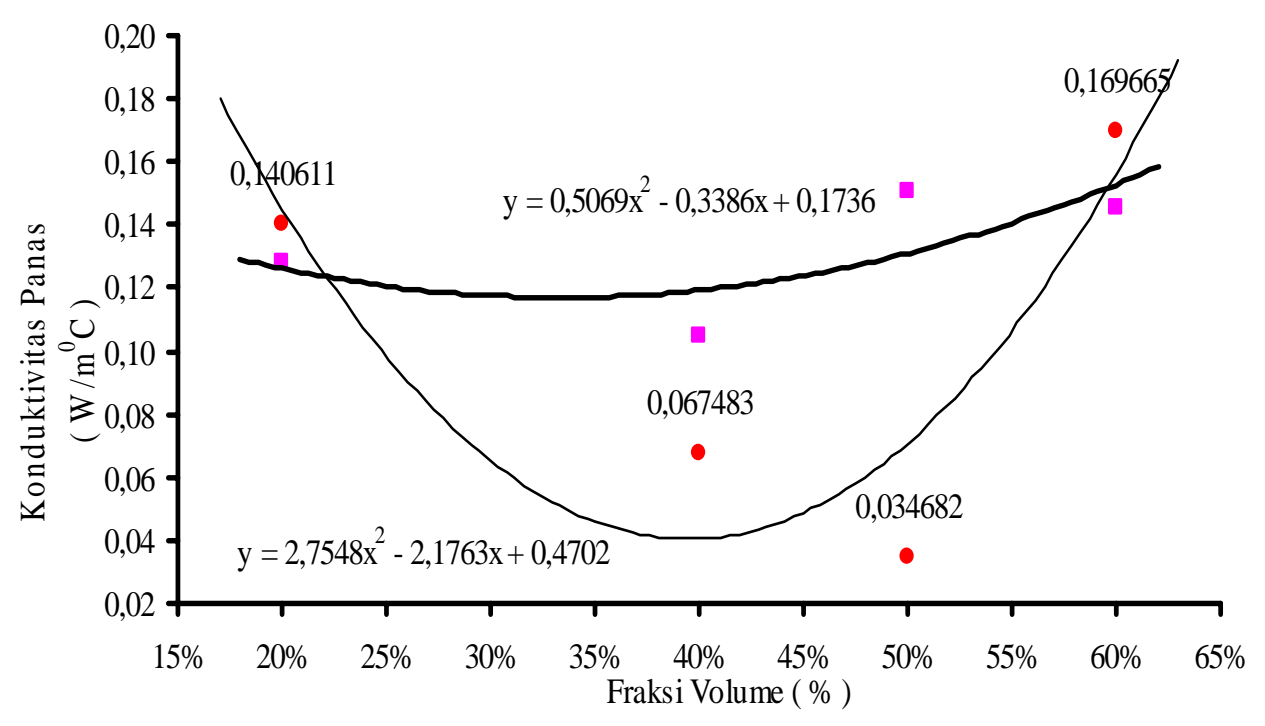

Gambar 9. Hubungan konduktivitas dengan suhu

\section{KESIMPULAN DAN SARAN}

\section{Kesimpulan.}

1. Perpindahan kalor pada komposit sangat ditentukan oleh prosentase serat dan matrik, semakin besar fraksi volume serat maka konduktivitas mengarah pada sifat serat.
2. Dengan model honeycomb maka nilai konduktivitas dapat menurunkan sehingga dapat menurunkan sifat ketergantungan pada matrik

\section{Saran}

Untuk memperoleh siaf hambat yang baik maka perlu pengembangan pengembangan model lubang dan pelapis lubang.

\section{DAFTAR PUSTAKA}

Gibson, R.F, 1994, Principle of Composite Material Mechanics, Department of Mechanical Engineering Wayne State University Detroit, Michigan, McGraw-Hill, Inc.

Mills, A.F.,1999, Basic Heat Mass Transfer, Second Edition, Universitas of California at Angeles Los Angeles, California.

Mazumdar, S.K., 2002, Composites Manufacturing Materials Product and Process Engineering, CRC Press LLC, 2000 N.W. Corporate Blvd., Boca Raton, Florida 33431.

Ngafwan, dan Diharjo, K.,2004, Pengaruh Kepadatan Core PVC pada Komposit Sandwich Serat Gelas Terhadap Peningkatan 